\title{
Studies on fast and slow growing Rhizobium spp. nodulating Cajanus cajan and Cicer arietinum
}

\author{
BY E. S. P. BROMFIELD* \\ Soil Microbiology Department, Rothamsted Experimental Station, Harpenden, Herts AL5 $2 J Q$, \\ England \\ AND J. V. D. K. KUMAR RAO \\ International Crops Research Institute for the Semi-Arid Tropics, Hyderabad, India
}

(Accepted 13 December 1982)

S UM M A R Y

Fast and slow growing Rhizobium spp. isolated from Cajanus cajan and Cicer arietinum were compared in terms of colony characteristics, utilisation of carbon sources, acid production, symbiotic effectiveness and nodulating competitiveness.

Fast growing isolates from $C$. cajan and $C$. arietinum formed 3-6 mm diameter colonies on yeast-extract mannitol agar after 4 days and were unlike the slow growers which produced colonies of $c$. $1 \mathrm{~mm}$ diameter after $7-10$ days at $28^{\circ} \mathrm{C}$. The fast growing Rhizobium spp. from C. cajan utilised a wider range of carbon sources than the slow growing isolates from this host. Fast and slow growing strains from $C$. arietinum were able to utilise most of the carbon sources tested suggesting that the slow growers possessed glycolytic pathways similar to those in other fast growing species of Rhizobium. In culture, slow growing isolates from C. cajan produced a near-neutral to alkaline reaction $(\mathrm{pH} 6 \cdot 6-7 \cdot 5)$ whereas the fast growers from this host and both fast and slow growing isolates from $C$. arietinum produced an acidic reaction (pH 4.4-5.6). These data are discussed in the context of Norris' (1965) evolutionary concept of the Leguminosae. Under glassshouse conditions, fast and slow growing strains isolated from $C$. cajan and C. arietinum were equally effective on their respective hosts.

In competition with slow growing rhizobia, half of the fast growers formed more than $70 \%$ of the nodules on C. cajan grown in sand. In all but one instance similar results were obtained when plants were grown in soil. With $C$. arietinum grown in sand or soil, all fast growing isolates from this host formed more than $85 \%$ of the nodules in competition with slow growing strains.

\section{INTRODUCTION}

The genus Rhizobium is divided into species mainly on the basis of preferred legume hosts which they nodulate (Vincent, 1974). However, in the classification of the rhizobia, Bergey (1974) uses growth rate as a taxonomic characteristic to further divide the genus into two sub-groups. According to Bergey (1974) the first of these groups ( $R$. phaseoli, $R$. leguminosarum, $R$. trifolii and $R$. meliloti) characteristically form $2-4 \mathrm{~mm}$ diameter colonies in 3-5 days at $c .25^{\circ} \mathrm{C}$ on yeast-extract mannitol agar whereas the second group ( $R$. lupini and $R$. japonicum) form small colonies (c. $1 \mathrm{~mm}$ diameter) after 7-10 days. However, in this classification Bergey (1974) does not consider a vast array of poorly defined rhizobia

* Present address: Chemistry and Biology Research Institute, Agriculture Canada. Ottawa, Ontario K 1 A OC6. 
(Rhizobium spp.) which constitute the so-called 'cowpea miscellany' and nodulate legumes (cowpea group) mostly of tropical or sub-tropical origin. Although legume hosts for the fast and slow growing rhizobia are usually distinct, several legumes mostly of the cowpea group are known to be nodulated by both fast and slow growing strains of the same species of Rhizobium. Lotus corniculatus (Vincent. Nutman \& Skinner, 1979) and L. pedunculatus (Pankhurst, 1977) are nodulated by both fast and slow growing Lotus rhizobia. Fast growing rhizobia have been isolated from Lablab purpureus (Trinick, 1980) and several species of Acacia (Dreyfus \& Dommergues, 1981) which are usually nodulated by slow growing strains. Glycine max usually nodulates with slow growing $R$. japonicum (Bergey, 1976) or Rhizobium spp. (Bromfield \& Roughley, 1980). However, several fast growing strains isolated from G. soja grown in China have been shown to nodulate G. $\max$ (Keyser, Bohlool. Hu \& Weber. 1982). Other fast growing rhizobia have been isolated from Cajanus cajan (Raju. 1938; Anon., 1980) and Cicer arietinum (Raju. 1936; Okon, Eshel \& Henis, 1972: Gaur \& Sen, 1981) which are frequently nodulated by slow growing Rhizobium spp. However, there have been no comparative studies on the properties of the fast growing rhizobia which nodulate $C$. cajan and $C$. arietinum with the more usual slow growing microsymbiont. This paper reports on the colony characteristics, acid or alkali production, utilisation of carbon sources, symbiotic effectiveness and nodulating competitiveness of fast and slow growing Rhizobium spp. isolated from C. cajan and C. arietinum.

MATERIALS AND METHODS

\section{Rhizobium strains}

The fast and slow growing Rhizobium spp. were isolated from Cajanus cajan or Cicer arietinum and obtained from the International Crops Research Institute for the Semi-arid Tropics. Hyderabad, India.

\section{Growth characteristics}

Colony sizes and morphological characteristics of Rhizobium spp. were recorded after 4, 7 or 10 days at $28^{\circ} \mathrm{C}$ on tryptone yeast-extract (TY) medium (Beringer, 1974) and yeast-extract mannitol agar (YEM) which was modified from Fred. Baldwin \& McCoy (1932) by using $1 \mathrm{~g} \mathrm{l}^{-1}$ dehydrated yeast-extract (Difco) and omission of $\mathrm{CaCO}_{3}$.

\section{Utilisation of carbon sources}

Thirty Rhizobium spp. consisting of 12 fast and 18 slow growing isolates from C. cajan and $C$. arietinum were tested for utilisation of 16 sources of carbon. Tests were carried out in a defined liquid medium modified from Ronson \& Primrose (1978) by using $\mathrm{KNO}_{3}$ as the nitrogen source at $0.6 \mathrm{~g} \mathrm{l}^{-1}$. The medium was dispensed aseptically in $5 \mathrm{ml}$ volumes to cotton-wool plugged glass tubes $(100 \times 12 \mathrm{~mm})$ and the appropriate carbon source (filter sterile) added to a final concentration of $0.4 \%(\mathrm{w} / \mathrm{v})$. Three replicate tubes for each strain and carbon source were inoculated with $50 \mu \mathrm{l}$ cell suspension $\left(c .10^{8} \mathrm{cells} \mathrm{ml}^{-1}\right.$ in sterile water) washed from the surface of a YEM slope. Controls consisted of liquid medium inoculated with each strain but lacking carbon source. The tubes were placed in an orbital shaker at $28^{\circ} \mathrm{C}$ for 7 days (fast growing isolates) or 14 days (slow growing isolates) and scored for growth ( $0-4$ scale) by comparison with appropriate controls.

\section{Acid production}

Thirty-two fast and slow growing Rhizobium spp. from C. cajan and C. arietinum were tested for acid production by the method of Norris (1965). The acid production medium was modified from Norris (1965) by using $1 \mathrm{~g}^{-1}$ dehydrated yeast-extract (Difco). Inocula were prepared by 
washing bacteria from the surface of YEM slopes in sterile water to give $c .10^{8}$ cells $\mathrm{ml}^{-1}$. Four replicate tubes were inoculated with $100 \mu \mathrm{l}$ cell suspension of each strain and randomised in racks.

\section{Symbiotic effectiveness tests}

Fast and slow growing Rhizobium spp. were tested for symbiotic effectiveness on C. cajan $c v$ ICP-1 or C. arietinum $c v$ G130. All seeds were surface sterilised (Vincent, 1970) and three of either host planted in $18 \mathrm{~cm}$ pots containing sterile sand and grit, $2: 1$ by volume. Immediately after planting, seeds of each host were inoculated with $1 \mathrm{ml}$ of a YEM broth suspension of the appropriate Rhizobium strain; uninoculated controls were included. After 2 wk growth in a glasshouse at $26{ }^{\circ} \mathrm{C}$ (day) $19{ }^{\circ} \mathrm{C}$ (night) the seedlings were thinned to two per pot. The pots were supplied with minus nitrogen solution (Summerfield, Huxley \& Minchin, 1977). To prevent cross-contamination by splashing, each pot was enclosed in a Polythene sleeve extending $10 \mathrm{~cm}$ from the surface of the sand and grit. The experimental design for each host inoculated with appropriate Rhizobium strains was a randomised complete block with four replications. Shoot dry weight, shoot $\mathrm{N} \%$ and nodule dry weight were determined $8 \mathrm{wk}$ after planting.

\section{Competition studies}

Competition for nodulation between fast and slow growing Rhizobium spp. was examined on C. cajan cv. ICP-1 and C. arietinum cv. G130. The procedure and design of the experiments was similar to the above except that each host was grown in sterilised sand and grit and in soil/sterilised sand and grit mixture ( $1: 1$ by volume). The soil was a sandy loam (pH 6.9, water) collected from Woburn, Bedfordshire and was deficient in native Rhizobium spp. able to nodulate C. cajan and C. arietinum. Intended 1:1 mixtures of broth cultures of fast and slow growing Rhizobium spp. were each inoculated onto five replicate pots of the appropriate host. The actual proportion of strains in the inocula were determined from colony counts on YEM agar (Vincent, 1970). For nodule strain identity, isolates were made using a sterile needle (Franco \& Vincent, 1970) and streaked on plates of YEM and TY medium. On these media fast and slow growing isolates of Rhizobium spp. could be readily differentiated by differences in morphology and growth rate; fast growing isolates appeared within 3-4 days whereas the slow growers took $7-10$ days at $28^{\circ} \mathrm{C}$.

RESULTS

\section{Colony characteristics}

The slow-growing Rhizobium spp. formed colonies $c .1 \mathrm{~mm}$ diameter on YEM and TY medium after 7 days (isolates from C. arietinum) and 10 days (isolates from C. cajan). Fast growing Rhizobium spp. from both legumes formed colonies $3-6 \mathrm{~mm}$ in diameter on these media after 4 days. Colonies of the fast growing isolates from C. cajan were spreading, runny and generally misty in appearance. Fast growing Rhizobium spp. from C. arietinum and slow growing isolates from both legumes produced colonies which were circular, convex with entire edges and white in appearance.

\section{Utilisation of carbon sources}

Table 1 shows data for the growth responses of fast and slow growing isolates from $C$. cajan and $C$. arietinum tested on 16 carbon sources. The fast growing isolates from $C$. cajan utilised a wider range of the carbon sources tested than the slow growing isolates from this host. However, of the ten fast growing isolates tested, two failed to utilise maltose, eight dulcitol and one lactose, rhamnose, raffinose and sucrose. Several carbon sources also gave slight growth responses (scores of 1 or 2) with up to two isolates. In contrast, only arabinose, xylose, sodium pyruvate 
Table 1. Response of fast and slow growing Rhizobium spp. isolated from Cajanus cajan and Cicer arietinum to 16 carbon sources

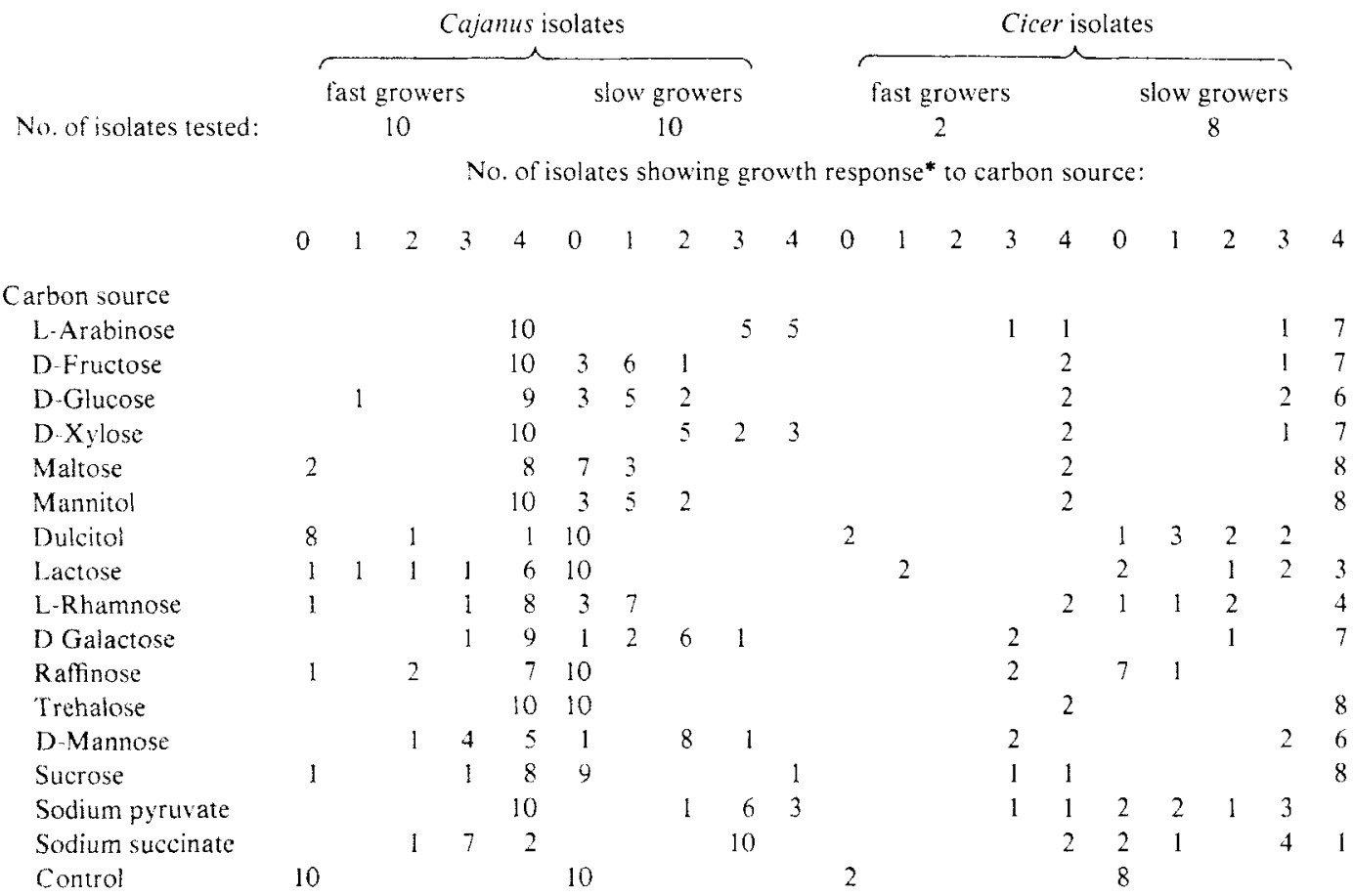

${ }^{*} 0$, no growth (equal to control lacking $\mathrm{C}$-source): 1, very slightly turbid: 2 . slight-moderate turbidity: 3 , turbid; 4. very turbid. Growth responses for each isolate are means of three replicates to the nearest whole number.

and sodium succinate were utilised by all slow growing isolates from C. cajan. Dulcitol, lactose, raffinose and trehalose did not support growth of any of these isolates and only one was able to utilise sucrose. Fast and slow growing isolates from $C$. arietinum were able to utilise most of the carbon sources tested although none of the fast growers utilised dulcitol and all showed only a slight growth response (scores of 1) with lactose.

Some slow growing isolates failed to utilise dulcitol, lactose, rhamnose, raffinose. sodium pyruvate and sodium succinate: several isolates showed only a slight growth response (scores of 1 or 2) with these carbon sources.

\section{Acid production}

Table 2 shows data for acid production on Norris' (1965) medium ( $\mathrm{pH} 7.2$ initially) by fast and slow growing isolates from $C$. cajan and $C$. arietinum. All fast growing isolates from $C$. cajan gave an acidic reaction ( $\mathrm{pH} 5 \cdot 2-5 \cdot 6)$ whereas the slow growers produced a near-neutral to alkaline reaction ( $\mathrm{pH} 6 \cdot 6-7 \cdot 5)$. There was variation in acid or alkali production within the fast and slowing growing isolates, e.g. IHP396 produced less acid $(P<0.01)$ than any of the fast growers and IHP2 and IHP20 produced more $(P<0.05)$ than all except IHP486; IHP309 produced more alkali $(P<0.01)$ than any of the slow growers and IHP41 and IHP53 less $(P<$ 0.01 ) than all except IHP 377 , IHP 156 and IHP456. The fast and slow growing isolates from $C$. arietinum all produced an acidic reaction (pH 4.4-5.6) on Norris' (1965) medium. Strains IC4. IC72 and IC 94 (slow growers) produced a less acidic reaction $(P<0.01)$ than the remaining fast and slow growing isolates. 
Table 2. Acid or alkali production by fast and slow growing Rhizobium spp. isolated from Cajanus cajan and Cicer arietinum

\begin{tabular}{|c|c|c|c|c|c|}
\hline \multicolumn{6}{|c|}{ Host of isolation: } \\
\hline \multicolumn{3}{|c|}{ C. cajan } & \multicolumn{3}{|c|}{ C. arietinum } \\
\hline Strain & Growth rate & final $\mathrm{pH}^{*}$ & Strain & Growth rate & final $\mathrm{pH}^{*}$ \\
\hline IHP509 & fast & 5.64 & IC 2073 & fast & $4 \cdot 64$ \\
\hline IHP2 & fast & $5 \cdot 16$ & IC 122 & fast & $4 \cdot 56$ \\
\hline IHP 100 & fast & $5 \cdot 44$ & IC 72 & slow & $5 \cdot 58$ \\
\hline IHP 170 & fast & $5 \cdot 32$ & IC74 & slow & $4 \cdot 76$ \\
\hline IHP20 & fast & $5 \cdot 18$ & IC4 & slow & $4 \cdot 38$ \\
\hline IHP396 & fast & $5 \cdot 84$ & IC55 & slow & $5 \cdot 10$ \\
\hline IHP502 & fast & $5 \cdot 60$ & IC76 & slow & $4 \cdot 56$ \\
\hline IHP307 & fast & $5 \cdot 32$ & IC 70 & slow & $4 \cdot 58$ \\
\hline IHP486 & fast & $5 \cdot 28$ & IC 2060 & slow & $4 \cdot 52$ \\
\hline IHP38 & slow & $7 \cdot 14$ & IC94 & slow & $5 \cdot 22$ \\
\hline IHP377 & slow & $6 \cdot 70$ & IC2028 & slow & $4 \cdot 78$ \\
\hline IHP37 & slow & 7.06 & $\mathrm{CBH} 32$ & slow & $4 \cdot 66$ \\
\hline IHP 156 & slow & $6 \cdot 74$ & IC 35 & slow & 4.48 \\
\hline IHP95 & slow & $7 \cdot 10$ & uninoculated & - & $7 \cdot 18$ \\
\hline IHP309 & slow & $7 \cdot 46$ & \multirow{6}{*}{\multicolumn{3}{|c|}{ S.E.D. $=0.093$ D.F. $=56$}} \\
\hline IHP41 & slow & 6.64 & & & \\
\hline IHP456 & slow & $6 \cdot 72$ & & & \\
\hline IHP53 & slow & 6.66 & & & \\
\hline IHP202 & slow & 6.92 & & & \\
\hline uninoculated & - & $7 \cdot 20$ & & & \\
\hline
\end{tabular}

\section{Symbiotic effectiveness}

Data for the symbiotic effectiveness of fast and slow growing Rhizobium spp. on C. cajan and $C$. arietinum are given in Table 3 . The fast and slow growing isolates from $C$. cajan produced more shoot dry matter and shoot $\mathrm{N} \%(P<0.01)$ than uninoculated plants and were equally effective on this host. The exceptions were IHP307 (fast growing isolate) which produced more $(P<0.05)$ shoot dry matter than IHP38 (slow growing isolate) and IHP38 and IHP309 (slow growers) which produced significantly higher shoot N\% $(P<0.05)$ than IHP2 and IHP486 (fast growers). Strains IHP38 and IHP377 formed black pigmented nodules similar to those previously reported (Anon., 1978) for several isolates from C. cajan. The fast and slow growing Rhizobium spp. tested on $C$. arietinum also produced significantly more $(P<0.01)$ shoot dry matter and shoot $\mathrm{N} \%$ than uninoculated plants and were equally effective. The only exception was IC72 (slow grower) which produced more shoot dry matter $(P<0.05)$ than IC2073 (fast grower).

\section{Competition studies}

Table 4 shows data for the proportion of strains in the nodules of $C$. cajan $\mathrm{cv}$. ICP-1 and $C$. arietinum $\mathrm{cv}$. G130 grown in sand or soil and inoculated with intended 1:1 mixtures of fast and slow growing Rhizobium spp. For strain identity, 30 nodules selected at random were taken from each of five replicates for each host grown in sand or soil and inoculated with each mixture of strains. Fast growing Rhizobium spp. formed the majority (70-80\%) of the nodules with half of the inoculated combinations of strains on $C$. cajan grown in sand, whereas slow growing isolates formed most of the nodules $(80-90 \%)$ with the remaining two inoculum mixtures. Similar results were obtained with $C$. cajan grown in soil except with one inoculum mixture 
Table 3. The response of Cajanus cajan, $c v$. ICP-1 and Cicer arietinum $c v . G 130$ to inoculation with fast or slow growing Rhizobium spp. (means of four replicates)

\begin{tabular}{|c|c|c|c|}
\hline Inoculum & $\begin{array}{l}\text { shoot dry weight } \\
\text { g plant }\end{array}$ & Shoot N\% & $\begin{array}{l}\text { Nodule dry weight } \\
\text { mg plant }\end{array}$ \\
\hline \multicolumn{4}{|c|}{ Host: C. cajan cv. ICP-1 } \\
\hline IHP2F* & 0.62 & $3 \cdot 13$ & 95 \\
\hline IHP307F & 0.73 & $3 \cdot 31$ & 119 \\
\hline IHP486F & 0.57 & $3 \cdot 21$ & 114 \\
\hline IHP509F & 0.61 & $3 \cdot 28$ & 111 \\
\hline IHP53S & 0.72 & 3.43 & 112 \\
\hline IHP38S & 0.59 & $3 \cdot 58$ & 97 \\
\hline IHP309S & 0.65 & 3.54 & 101 \\
\hline IHP377S & 0.68 & $3 \cdot 40$ & 107 \\
\hline uninoculated & 0.41 & 1.92 & - \\
\hline S.E.D. & 0.08 & 0.15 & $14 \cdot 65$ \\
\hline & D.F. $=24$ & D.F. $=24$ & D.F. $=21$ \\
\hline \multicolumn{4}{|c|}{ Host: C. arietinum cv. G1 30} \\
\hline IC $2073 F$ & 0.98 & $3 \cdot 55$ & 110 \\
\hline IC $122 \mathrm{~F}$ & $1 \cdot 10$ & 3.67 & 122 \\
\hline $\mathrm{IC} 72 \mathrm{~S}$ & 1.25 & 3.71 & 154 \\
\hline $\mathrm{IC} 74 \mathrm{~S}$ & 1.00 & $3 \cdot 48$ & 134 \\
\hline uninoculated & 0.69 & $2 \cdot 12$ & - \\
\hline \multirow[t]{2}{*}{ S.E.D. } & $0 \cdot 11$ & 0.13 & 18.47 \\
\hline & D.F. $=12$ & D.F. $=12$ & D.F. $=9$ \\
\hline
\end{tabular}

Table 4. Proportion of nodules on Cajanus cajan $c v$. ICP-I and Cicer arietinum $c v$. GI30 grown in sand or soil and inoculated with mixtures of fast and slow growing Rhizobium spp.

\begin{tabular}{|c|c|c|c|c|}
\hline \multirow{2}{*}{$\begin{array}{l}\text { Inoculum } \\
\text { (fast growing } \\
\text { strain + slow } \\
\text { growing strain) }\end{array}$} & \multirow[b]{2}{*}{ Host } & \multirow{2}{*}{$\begin{array}{l}\% \text { fast growing } \\
\text { strain in inoculum }\end{array}$} & \multicolumn{2}{|c|}{$\begin{array}{l}\text { \% nodules due } \\
\text { to fast growing } \\
\text { strain on plants } \\
\text { grown in: }\end{array}$} \\
\hline & & & sand & soil \\
\hline IHP486 + IHP309 & C. cajan & 58 & $72^{*}$ & $39 * *$ \\
\hline IHP509 + IHP377 & C. cajan & 57 & $81^{* *}$ & $77^{* *}$ \\
\hline $1 \mathrm{HP} 307+1 \mathrm{HP} 38$ & C. cajan & 43 & $23^{* *}$ & $20^{* *}$ \\
\hline IHP2 + IHP53 & C.cajan & 54 & $8^{* *}$ & $19^{* *}$ \\
\hline IC $2073+$ IC 72 & C. arietinum & 72 & $89^{* *}$ & $94^{* *}$ \\
\hline IC $122+1 \mathrm{C} 74$ & C. arietinum & 71 & $86^{* *}$ & $98^{* *}$ \\
\hline
\end{tabular}

Asterisks denote level of significance $\left({ }^{*} . P<0.05\right.$ : $\left.^{* *}, P<0.01\right)$ in $\chi^{2}$ tests (D.F. = 1 ) comparing ratios of strains in each inoculum with those in nodules of plants grown in sand or soil.

(1HP486 + IHP309) where the majority of the nodules were formed by the slow growing strain contrasting to a majority formed by the fast grower on this host grown in sand. Chi squared analyses showed that in every instance the ratios of strains in the nodules deviated significantly from the ratio in each inoculum due to either fast or slow growing strains producing the majority of the nodules.

The fast growing strain in each inoculum mixture formed the majority of the nodules on $C$. arietinum grown in sand or soil. Chi squared analyses showed that the ratios of strains in the nodules deviated $(P<0.01)$ from the ratios in the inocula. 


\section{DISCUSSION}

The fast growing Rhizobium spp. from C. cajan and C. arietinum used in this investigation produced 3-6 mm diameter colonies after 4 days and were quite unlike slow growing isolates which formed c. $1 \mathrm{~mm}$ diameter colonies after 7-10 days. Fast growing species of Rhizobium have been reported to utilise a wide range of carbon sources whereas slow growing species are more specialised in their requirements (Vincent, 1974). The fast growing Rhizobium spp. isolated from $C$. cajan and used in our experiments similarly demonstrated very different carbon source utilisation and were able to grow with a wider range of these compounds than the slow growing isolates from this host. However, most fast and slow growing isolates from C. arietinum were able to utilise the majority of carbon compounds tested. In this respect the slow growing isolates from C. arietinum differ from the other slow growing species of Rhizobium (Graham, 1964; Glenn \& Dilworth, 1981) in their ability to utilise disaccharides. This suggests that the slow growing isolates from $C$. arietinum possess disaccharide hydrolytic enzymes and uptake systems similar to those reported for the fast growers (Glenn \& Dilworth, 1981).

According to the evolutionary concept of the Leguminosae (Norris, 1965), the slow growing alkali producing Rhizobium represents the 'ancestral' form and is typically associated with symbiotically unspecialised tropical legumes inhabiting acid soils of low exchange capacity. The fast growing acid producing species of Rhizobium are considered to be associated with the taxonomically advanced temperate legumes which are specific in their nodulating requirements and have a special requirement for high soil $\mathrm{pH}$, available calcium and nutrient status. The slow growing isolates from $C$. cajan used in our experiments produced an alkaline reaction in culture in accordance with this concept. However, all the fast growing isolates from C. cajan were acid producers and may represent intermediate forms between the 'ancestral' Rhizobium as defined by Norris (1965) and the fast growing species ( $R$. leguminosarum, $R$. phaseoli, $R$. trifolii and $R$. meliloti) which form a symbiosis with the taxonomically advanced and symbiotically specialised temperate legumes. The fact that the fast growing Cajanus isolates were as effective in nitrogen fixation as the slow growers on this host indicates that this was not a 'relic association' which Norris (1965) describes as being occasionally formed by fast growing species of Rhizobium retaining their 'ancestral' ability to nodulate tropical legumes whilst normally losing their capacity to form an effective symbiosis. Norris (1965) also considers that symbiotic specialisation of the host is strongly correlated with acid production by its characteristic Rhizobium. Our finding that the fast and slow growing isolates from $C$. arietinum were acid producers and the fact that this host is highly specific in its nodulating requirements (Guar \& Sen, 1979) lends support to this concept.

The method used in this paper to identify strains in nodules, based on differences in growth rate, did not permit the detection of double strain occupancy of nodules involving fast and slow growing isolates because the slow growing component tended to be overgrown on reisolation by the fast growing strain. However, Bromfield \& Jones (1980) have demonstrated that dual strain occupancy of nodules is of rare occurrence in soil. The results of the competition studies with $C$. cajan and $C$. arietinum showed that in all but one instance the proportion of nodules formed by fast growing strains on plants grown in sand was similar to or less than the proportion on plants grown in soil indicating that double infections involving fast and slow growers occurred infrequently in sand. However, the single aberrant result with $C$. cajan where a fast growing strain (IHP486) formed a greater proportion of nodules in sand than in soil may have been partly due to undetected double infections on the plants grown in sand.

If the fast growing isolates from $C$. cajan are considered intermediate forms between the 'ancestral' and 'advanced' Rhizobium as defined by Norris (1965) then it might be expected that competition for nodulation between fast and slow growers would reveal almost exclusive selection by the host for the slow growing strains. However, our results showed that half of the fast growing isolates when inoculated in mixtures with slow growers, formed the majority of 
nodules on $C$. cajan perhaps indicating an even closer evolutionary relationship with the slow growing, alkali producing rhizobia which nodulate tropical legumes.

With C. arietinum, all fast growing isolates inoculated in mixtures with slow growers, formed the majority of nodules, a result which when considered in conjunction with their symbiotic efficiency suggests a high degree of compatibility with this host.

Although only a limited number of strains were examined, it is probable on the basis of these results that indigenous fast growing rhizobia able to nodulate $C$. arietinum are more frequently encountered than normally anticipated and may have been unconsciously excluded from culture collections because their morphology deviates from the slow growing type usually expected to be associated with this host.

In this respect a field survey determining the proportion of fast and slow growing isolates able to nodulate $C$. arietinum might well repay investigation.

Financial support provided by the Overseas Development Administration for the work carried out at Rothamsted is acknowledged.

\section{REFERENCES}

ANON. (1978). Annual Report 1976-1977. International Crops Research Institute for the Semi Arid Tropics, Hyderabad, India, p. 81.

ANON. (1980). Annual Report 1978-1979. International Crops Research Institute for the Semı Arid Tropics. Hyderabad, India. p. 112

BERINGER, J. E. (1974). R-factor transfer in Rhizobium leguminosarum. Journal of General Microbiology 84. $188-198$.

BERGEY, G. H. (1974). Bergey's Manual of Determinative Bacteriology, 8th Edition, pp. 261-265. Eds R. E. Buchanan \& N. E. Gibbons. Baltimore: Williams \& Wilkins Co.

BROMFIELD. E. S. P. \& JONES. D. G. (1980). Studies on double strain occupancy of nodules and the competitive ability of Rhizobium trifolii on red and white clover grown in soil and agar. Annals of Applied Biology 94. 51-59.

BRomfield. E. S. P. \& ROUGHLEY, R. J. (1980). Characterisation of rhizobia isolated from nodules on locally adapted Glycine max grown in Nigeria. Annals of Applied Biology, 95, 185-190.

DREYfuS, B. L. \& DOMmergues, Y. R. (1981). Nodulation of Acacia species by fast and slow growing tropical strains of Rhizobium. Applied and Environmental Microbiology 41, 97-99.

FRANCO, A. A. \& VINCENT, J. M. (1976). Competition amongst rhizobial strains for the colonisation and nodulation of two tropical legumes. Plant and Soil 45, 27-48.

FRED, E. B., BALDWN, I. L. \& MCCOY, E. (1932). Root-nodule bacteria and leguminous plants. University of Wisconsin. Studies in Science. No. 5. Madison.

G.AUR, Y. D. \& SEN. A. N. (1979). Cross inoculation group specificity in Cicer-Rhizobium symbiosis. New Phytologist 83. 745-754.

GAUR. Y. D. \& SEN. A. N. (1981). Cultural and Biochemical characteristics of root-nodule bacteria of Chickpea (Cicer arietinum L.). Zentralblatt für Bakteriologie, Parasitenkunde, Infektionskrankheiten und H'giene, Abteilung II 136, 307-316.

GL.ENN. A. R. \& DILWORTH. M. J. (1981). The uptake and hydrolysis of disaccharides by fast and slow growing species of Rhizobium. Archices of Microbiology 129. 233-239.

GRAHAM. P. H. (1964). Studies on the utilization of carbohydrates and Krebs cycle intermediates by rhizobia using an agar plate method. Antonie ran Leeuwenhoek 30, 68-72.

KEYSER, H. H., BOHLOOL, B. B., HU. T. S. \& WEBER, D. F. (1982). Fast growing rhizobia isolated from root nodules of soybean. Science 215. 1631-1632.

NORRIS, D. O. (1965). Acid production by Rhizobium a unifying concept. Plant and Soil 22, 143-166.

OKON, Y., ESHEL, Y. \& HENIS, Y. (1972). Cultural and symbiotic properties of Rhizobium strains isolated from nodules of Cicer arietinum L. Soil Biology and Biochemistry 4. 165-170.

PaNkHLRST. C. F. (1977). Symbiotic effectiveness of antibiotic resistant mutants of fast and slow growing strains of Rhizobium nodulating Lotus species. Canadian Journal of Microbiology 23. $1026-1033$. 
RAJU, M. S. (1936). Studies on the bacterial plant groups of Cowpea, Cicer and Dhaincha. I. Classification. Zentralblatt für Bakteriologie, Parasitenkunde, Infectionskrankheiten und Hygiene, Abteilung II 94, 249-262.

RAJU, M. S. (1938). Studies on the bacterial plant groups. IV. Variations in the fermentation characters of different strains of nodule bacteria of Cowpea, Cicer and Dhaincha groups. Zentralblatt für Bakteriologie, Parasitenkunde, Infectionskrankheiten und Hygiene, Abteilung II 99, 133-141.

RONSON, C. W. \& PRIMROSE, S. B. (1979). Carbohydrate metabolism in Rhizobium trifolit. Identification and symbiotic properties of mutants. Journal of General Microbiology 112, 77-88.

SUMMERFIELD, R. J., HUXLEY, P. A. \& MINCHIN, F. R. (1977). Plant husbandry and management techniques for growing grain legumes under simulated tropical conditions in controlled environments. Experimental Agriculture 13, 81-92.

TRINICK, M. J. (1980). Relationships amongst the fast growing rhizobia of Lablab purpureus, Leucaena leucocephala, Mimosa spp. Acacia farnesiana and Sesbania grandiflora and their affinities with other rhizobial groups. Journal of Applied Bacteriology 49, 39-53.

vinCENT, J. M. (1970). A manual for the Practical Study of Root Nodule Bacteria. IBP Handbook No. 15. Blackwell Scientific Publications, Oxford. $164 \mathrm{pp}$.

VINCENT, J. M. (1974). Root nodule symbiosis with Rhizobium. In The Biology of Nitrogen Fixation. Ed. A. Quispel. North Holland Research Monographs, Frontiers of Biology, Vol. 33, Amsterdam: North Holland.

VINCENT, J. M., NUTMAN, P. S. \& SKINNER, F. A. (1979). The identification and classification of Rhizobium. In Identification methods for Microbiologists. Eds F. A. Skinner \& D. W. Lovelock. The Society for Applied Bacteriology Technical Series No. 14. London: Academic Press. 